\title{
COVID-19 in Italy: An Overview from the First Case to Date
}

\author{
Luigi Santacroce ${ }^{1 \star}$, loannis Alexandros Charitos ${ }^{2}$, Raffaele Del Prete ${ }^{3}$
}

\author{
${ }^{1}$ Ionian Department, Microbiology and Virology Lab., University Hospital of Bari, Bari, ITALY \\ ${ }^{2}$ Regional Emergency Service, National Poisoning Center, University Hospital of Foggia, Foggia, ITALY \\ ${ }^{3}$ Department of Interdisciplinary Medicine, Section of Microbiology and Virology, University Hospital of Bari, Bari, ITALY \\ *Corresponding Author: luigi.santacroce@uniba.it
}

Citation: Santacroce L, Charitos IA, Del Prete R. COVID-19 in Italy: An Overview from the First Case to Date. Electron J Gen Med. $2020 ; 17(6)$ :em235. https://doi.org/10.29333/ejgm/7926

\begin{tabular}{ll}
\hline ARTICLE INFO & ABSTRACT \\
\cline { 1 - 2 } Received: 2 Apr. 2020 & $\begin{array}{l}\text { This paper is aimed to point out the current state of the COVID-19 pandemics in Italy. Currently, COVID-19 is an } \\
\text { international crisis and all the continents have recorded a certain number of cases to date. After the first report of } \\
\text { Accepted: 7 Apr. 2020 }\end{array}$ \\
$\begin{array}{l}\text { such infectious threat in China, the disease has progressively widespread thorough the world, and all the countries } \\
\text { have attempted to point out specific protocols and therapies to face this new, unknown condition. The authors } \\
\text { report an overview of how the Italian health service is facing this crisis after two months from the first internal } \\
\text { reported cases. At last, special considerations highlight the non-sanitary issues of COVID-19 outbreak in Italy. }\end{array}$
\end{tabular}

Keywords: COVID-19, Coronavirus, SARS-CoV-2, pandemic, Italy outbreak, healh policy, health funding

\section{INTRODUCTION}

The "severe acute respiratory syndrome coronavirus 2" (SARS-CoV-2), officially named as "Coronavirus Disease-2019 (COVID-19)" by World Health Organization (WHO) on February 11,2020 (1) is actually the new coronavirus culpable of one of the most severe worldwide pandemic in recent history. On December 31, 2019, the WHO China Country Office documented many cases of unknown origin pneumonia in the city of Wuhan, in the Hubei Province. A new type of Chinese Coronavirus, the SARS-CoV-2, was isolated on January 7, 2020 and its genetic sequence was shared with the rest of the world in order to develop specific diagnostic kits and to fight this new battle together. Other possible etiological agents such as flu, avian influenza, adenovirus infection, Severe Acute Respiratory Syndrome coronavirus (SARS-CoV) and Middle East Respiratory Syndrome coronavirus (MERS-CoV) were previously excluded (2-4). Coronaviruses are non-cultivable, positive single stranded RNA viruses, with helical nucleocapsid and a lipid envelope, belonging to the family Picornaviridae, usually accounting for animal (i.e., cattles, bats, etc.) diseases. The term Coronavirus refers to the characteristic "crown-like" morphology of its envelope, resembling the mantle of Our Lady of Guadalupe, dates 1968, but the first report of a human coronavirus isolation dates 1965 from child nasal washings $(5,6)$. In humans, we currently know seven genotypes of Coronaviruses (HCoV) and four sub-groups (alpha, beta, gamma, and delta). The commonest are four (229E, OC43, NL63, HKU1), usually able to induce common cold, peaking in cold months. During the two last decades other three genotypes have been identified (SARS-CoV, MERS-CoV and 2019-nCoV), all of them animal viruses evolved and able to infect humans causing severe pneumonias. For common types of Coronaviruses, the immune response is not lifelong, so re- infections can occur during the years, mainly in immunocompromised people.

Differential diagnosis with other microorganisms usually involved in respiratory diseases is possible by laboratory tests on nasal swabs, similar to those for other commonest viruses, based on multiplex real-time reverse transcription-PCR (RT$\mathrm{PCR}$ ) methods that allows the detection of viral genome (the longest and largest of any RNA virus), and titering inflammation-related molecules (7-9). Therapies are not specific, mainly focused to minimize respiratory distress and the risk of death $(10,11)$.

On January 21, 2020 a total of 314 confirmed cases of novel coronavirus infections have been reported in the world, 309 from China, while the other 5 were imported cases in Thailand (2), Japan and in the Republic of Korea (3). From that moment, the number of reported, confirmed cases of COVID-19 contagions significantly increased all over the world and the WHO declared the outbreak to be "a public health emergency of international concern." Strong measures for all nations were provided by the Emergency Committee on the novel coronavirus (2019-nCoV) in order to detect the disease as early as possible, isolate and treat new cases, trace contacts of symptomatic and asymptomatic patients, and promote social distancing measures on the web, by media and social media.

\section{THE ITALIAN OUTBREAK OF COVID-19}

On January 31, 2020, after 102 years from the Spanish flu pandemic, with an estimated number of Italian deaths of 410,000 in 1918 (which raised to 466,00 up to 1920) (12), the first two confirmed cases of infection due to 2019-nCoV were reported in Rome, Italy (6); both patients, a Chinese couple, had travel history to Wuhan City; they isolated in quarantine 
Total confirmed cases (blue line) and total deaths (red line) from COVID-19 in Italy

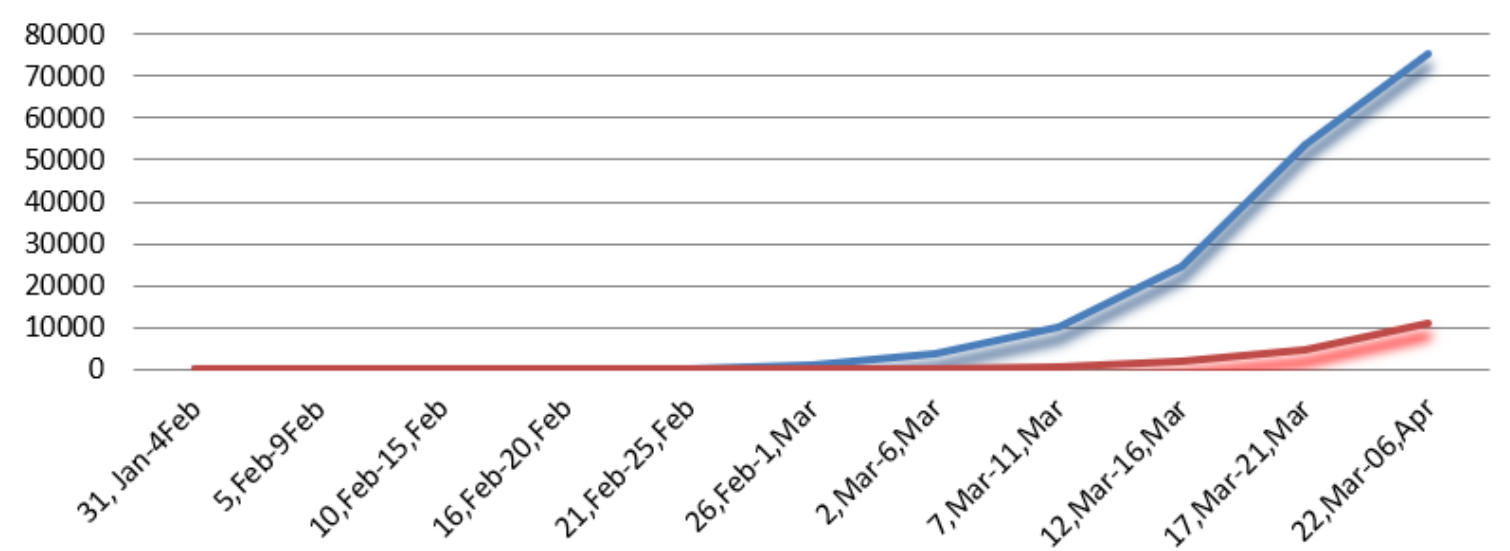

Figure 1. Graphic shows the exponential growth of contagion in the Italian Regions and total deaths due to COVID-19 infection on April 6, 2020 (from January 31, 2020, source W.H.O.)

and treated in the 'Lazzaro Spallanzani' National Institute for Infectious Diseases-IRCCS, Rome, Italy (13). That day, total confirmed cases were 9826 worldwide. In China, $60.5 \%$ of all cases since the start of the outbreak were reported from Hubei Province (14).

On February 13, 2020, a total of 170 patients in 24 Countries outside of China, but with a travel history to China, resulted positive to COVID-19 (7). In the mid-February, Italian confirmed cases were 3, and all of them had a travel history to China or contacts with someone coming from China (15).

General but fundamental best practices were widely diffused on Web and by official media to decrease the general risk of transmission of acute respiratory infections. These behaviour rules included: avoiding close contact with other people, especially those suffering from acute respiratory symptoms (fever, cough, sneezes), frequent hand-washing, especially after contact with crowded environments or with ill people, covering coughs and sneezes with disposable tissues and enhancing standard infection prevention and control practices in hospitals, especially in Emergency Departments. People were encouraged to seek medical attention in case of symptoms suggestive of respiratory illness either during or after travels (16).

Meanwhile, the rapid spread of COVID-19 infection brought the International Community to accelerate researches on new strategies of interventions, including effective tests, vaccines and therapeutics and to share critical scientific data to ensure that those affected were promptly diagnosed, receiving optimal care. Scientists from everywhere in the world worked together to find a global strategy against this dramatic increase in cases: from 11 to 12 February 2020, almost 400 world scientists met at WHO's Geneva Headquarters to discuss the current level of knowledge about the COVID-19 virus (transmission route, epidemiological studies, natural history of the disease, researches on its origins) but also to identify new strategies to prepare the world for future outbreaks, including clinical management, infection prevention and control measures in both individuals and healthcare workers, candidate therapeutics and vaccines (16).

The expansion of COVID-19 outbreak in Italy began in northern Italy, more precisely in Lombardy where the higher incidence of the coronavirus contagion is currently active extending throughout the area of the Po Valley and, subsequently in the whole country after about one month. On
February 22, 2020 a total of 9 cases (including 6 new diagnosed) and the first death of a patient were confirmed in Italy. In the same day, 76,392 were the confirmed Chinese cases since the outbreaks, with 2,348 total deaths, and 697 cases throughout the world, with 11 deaths (17). Italy locked down at least ten towns in the northern part of Lombardy, particularly Codogno, and the epicentre of the Veneto cluster, Vo'Euganeo. The mayor of Codogno quickly issued a decree ordering the closure of all public activities, such as restaurants, coffee bars, gyms, schools and public gathering spots for a general quarantine. The Health Ministry advised the residents of Northern Italian regions (particularly Lombardy, Piedmont, Veneto) to stay home as a precaution to avoid further viral widespread. Police checkpoints surrounded quarantined towns and regulated customer queues at supermarkets. Italian Civil Protection urged Italians to abide by the containment measures for the two weeks quarantine period. On February 26, 2020, for the first time since the onset of symptoms in the first identified case of COVID-19 in China on December 2019, there have been more new cases reported from countries outside of China than from China itself. In Italy there were 322 confirmed cases, with a total of 11 deaths (18). Many of the new cases were infections acquired through a contagion with asymptomatic patients. Mr. Giuseppe Conte, the Italian Prime Minister, called for several meetings all Italian government Ministers and regional Governors to designate all together a coordinated plan for fighting against the spread of the new coronavirus across the country. On March 11, 2020 the WHO Director-General, deeply concerned both by the alarming levels of spread and severity, declared that COVID-19 can be characterized as a pandemic (19). Currently, on April 6, 2020, Italy counts (Figure 1) a total of 128,948 (including 12,252 health workers) COVID-19 confirmed cases with 15,889 deaths from the beginning of the COVID-19 epidemic (Figure 2), with a total lethality of $12 \%$ (Table 1) $(20,21)$.

Based on the trend of COVID-19 infection in Italy and in Europe, and the spread of pandemic throughout the world, the Italian Government ordered many restrictions to the whole country in order to contain and limit the further spread of Covid-19 (Coronavirus) in Italy and in the rest of the world by travellers. First and most important recommendation is to stay at home as much as possible. The Decrees by Prime Minister, dated March 8, 2020, March 9, 2020 (22) and March 11, 2020 (23) established many restrictions to the whole country, in force from 12 to 25 March 2020: to avoid further spread of contagion, 


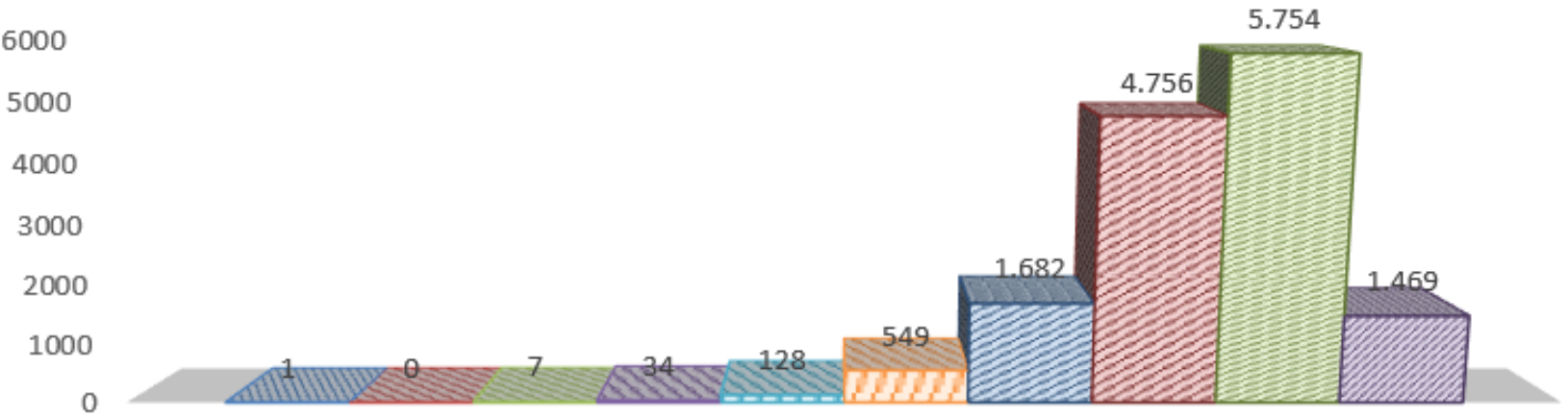

Figure 2. Graphic shows the deaths comparison within age groups in Italy on April 5, 2020 (from January 31, 2020). It is noteworthy that the highest mortality has been recorded in the $9^{\text {th }}$ decade (source Epicentro, Istituto Superiore di Sanità, Italy)

Table 1. Comparison of lethality and deaths percentages in different age groups in Italy on April 5, 2020 (from January 31, 2020). It is noteworthy that the age groups over 70 yo show the higher lethality risk (source Epicentro, Istituto Superiore di Sanità, Italy)

\begin{tabular}{ccc}
\hline Age groups & Deaths (\%) & Lethality (\%) \\
\hline $0-9$ & $0 \%$ & $0.1 \%$ \\
\hline $10-19$ & $0 \%$ & $0 \%$ \\
\hline $20-29$ & $0 \%$ & $0.1 \%$ \\
\hline $30-39$ & $0.2 \%$ & $0.4 \%$ \\
\hline $40-49$ & $0.9 \%$ & $0.8 \%$ \\
\hline $50-59$ & $3.8 \%$ & $2.3 \%$ \\
\hline $60-69$ & $11.7 \%$ & $8.5 \%$ \\
\hline $70-79$ & $33.1 \%$ & $22.6 \%$ \\
\hline $80-89$ & $40 \%$ & $30.8 \%$ \\
\hline $90 \geq$ & $10.2 \%$ & $27.4 \%$ \\
\hline Unknown & $0 \%$ & $0.6 \%$ \\
\hline
\end{tabular}

people must avoid any movement to and from all regions with the exception of justified business reasons, urgent circumstances or because of substantiated health reasons or health emergencies; all travel must be legitimate by a selfdeclaration. The Decrees stated the closure of schools of every degree and order, the stop of public events (sporting, musical, religious, cultural), all not strictly necessary business activities with the exception of grocery stores and shops selling consumer staples, pharmacies and para-pharmacies, shops selling medical and orthopaedic articles, and other basic necessities stores and offices. All open shops and allowed businesses had to guarantee a safety distance of at least one meter (22-24).

Evidence to date suggests that COVID-19 virus infects people of all ages: the risk of getting severe disease and pulmonary complications gradually increases with age starting from around 40 years and it is maximal from around 60 years old, but it also involved those patients with underlying medical conditions (such as chronic respiratory disease, cardiovascular disease, diabetes, immunodepression/immunosuppression and cancer) (25). WHO underlines that all people (healthy or otherwise) must protect themselves from COVID-19 infection in order to protect the whole population. Current information suggest that the route of human-to-human transmission of COVID-19 is either via respiratory droplets or close contact (e.g. sneezing, coughing, etc.), so International Health Agencies, Italian Government, Regional politics and media recommend maximum precautions and stress the importance for all communities to protect themselves and others by staying in their homes, by the use of personal protective equipment (medical masks, gloves) as a prevention measures to limit the spread of respiratory and contact contagions, combined with other measures to prevent human-to-human transmission such as avoiding people aggregations and crowded spaces, maintaining distance of at least one meter from any person, particularly if with respiratory symptoms, performing hand hygiene frequently, using soap and hot water if possible, or an alcohol-based hand rub in public places, covering nose and mouth with a disposable paper tissue if coughing or sneezing, disposing of the tissue directly after use and immediately performing hand hygiene, refraining from touching their mouth and nose in public places $(25,26)$.

In an analysis based on 14,860 patients in Italy, both deceased and COVID-19 positive, the most common ongoing disease in the deceased patients were, in order: 1) high blood pressure, 2) ischemic heart disease, 3) atrial fibrillation, 4) type 2 diabetes mellitus, 5) heart failure, 6) obstructive pulmonary conditions (COPD), 7) stroke, 8) chronic kidney failure, 9) cancer history in the past 5 years, 10) dementia and finally 11) chronic liver diseases.

The most common symptoms reported at the onset were: fever (76\%), dyspnoea (72\%), coughing (39\%), diarrhoea (6\%) and haemoptysis (1\%). Indeed, individuals with suspected symptoms (fever, cough, difficulty breathing) should promptly wear a surgical protective mask (but also their family and close contacts) and seek medical care as soon as possible. Local medical authorities should follow and adopt specific WHO recommendations to identify and isolate suspected cases of COVID-19, including clinical exam to determine the need for hospital admission or for home testing for COVID-19 and subsequent isolation (26-28). Therefore, isolation at home of people presenting with mild or moderate symptoms (i.e., flu like symptoms) is recommended (if without risk factors), contacting the family physician for advice on therapy after possible COVID-19 test execution, also to those who have had close contact with other sick or suspected people (e.g., family members, work colleagues etc.) according to the WHO guide (29). Red areas (high risk of contagions) have been created in the various cities. It has been also observed that family members get sick synchronously or metachronous. During the hospital stay therapies are mainly based on antibiotics (85\% of cases), antivirals (55\%) and steroids (33\%). The common use of antibiotic therapy can be justified by the presence of superinfections, or if compatible with the empirical therapy in patients with pneumonia while pending laboratory confirmation for COVID-19. 


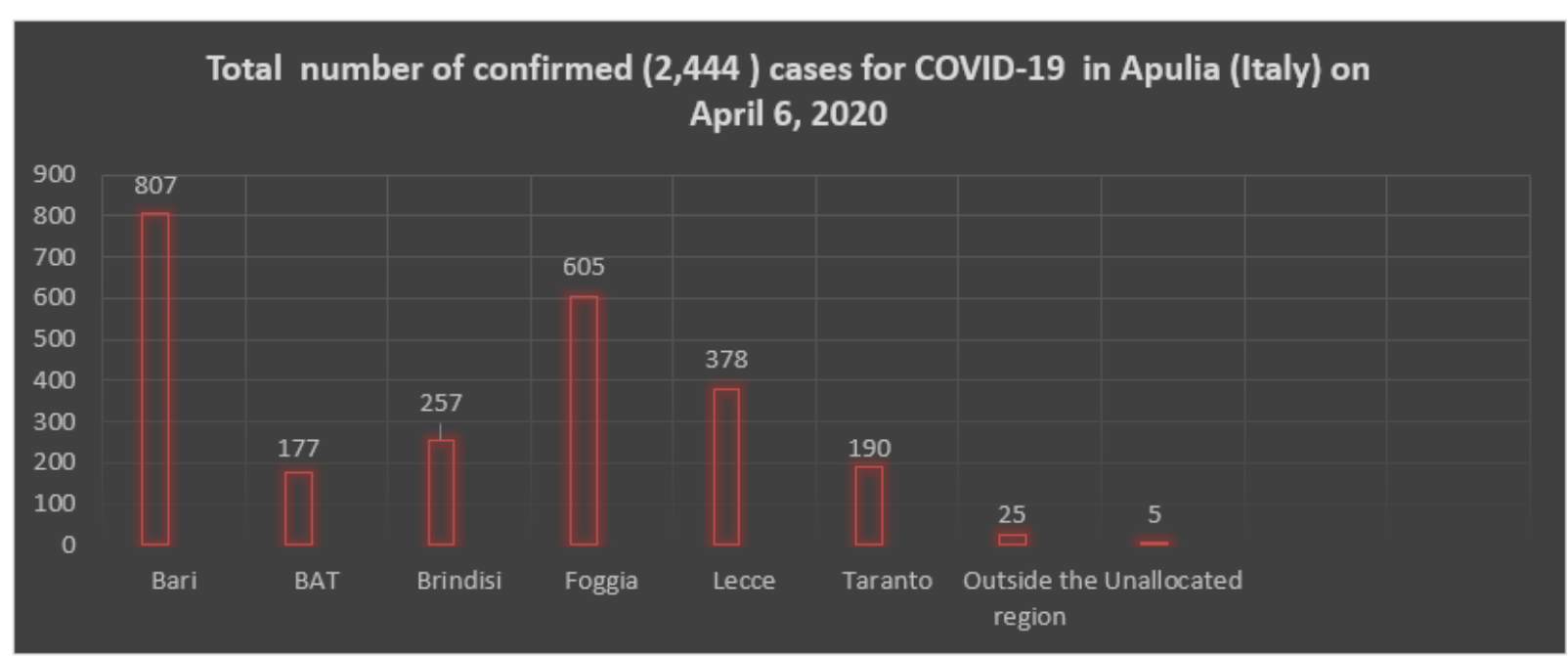

Figure 3. The number of positive cases in Apulia on April 6, 2020 (source Bollettino epidemiologico Regione Puglia 06/04/2020, Italy)

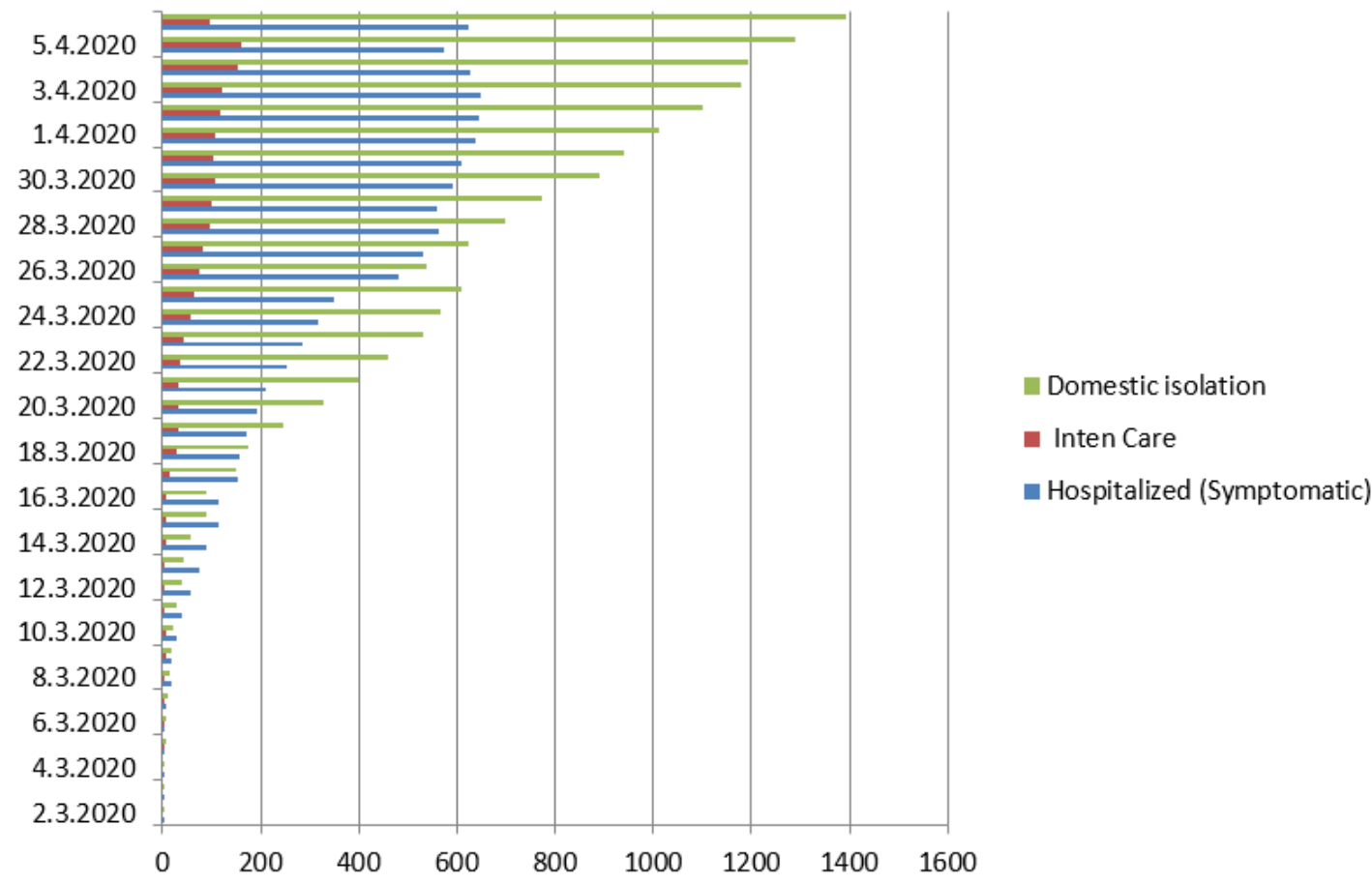

Figure 4. The graphic shows the relationship between the emergency days and the cases of domestic isolation, hospitalization of symptomatic patients, and those hosted in intensive care unit (source Bollettino epidemiologico Regione Puglia 06/04/2020, Italy)

In 198 cases $(18.0 \%)$ all 3 therapies were used and in the $1.9 \%$ of the deceased patients was given Tocilizumab, a monoclonal antibody effective to block the lung receptors of interleukin-6 (IL6-r), responsible for pulmonary fibrosis in such patients. Furthermore, in patients with severe respiratory failure, non-invasive or mechanical ventilation was performed by intubation or, subsequently a tracheostomy, for the long standing mechanical ventilation.

The complications that led to the patients' death were: respiratory failure (96.1\% of cases), acute kidney damage $(25.0 \%)$, superinfections $(10.6 \%)$ and acute myocardial damage (10.4\%).

To date 22,187 patients have been discharged and cured (27).

The intensive care units (ICUs) in Northern Italy are on the brink of collapse, particularly those of Lombardy (Bergamo,
Brescia, Cremona, Lodi), epicentre of the Italian epidemic, but also Piedmont, Veneto, Emilia-Romagna's ICUs. Before this crisis, total ICUs capacity has been actually increased with public and private funds, but further and constant measures for containment are the fundamental way to coordinate the critical care response to the outbreak and to deal with the emergency. Many other mild symptomatic or at-risk patients are in lockdown quarantine in their houses (27-30).

Till now 22,059 COVID-19 tests have been performed in Apulia since the beginning of the pandemic emergency, and the total number of positives are 2,444 cases (Figure 3), with 195 total deaths and 134 healed patients. A total of 625 patients were hospitalized, 95 in intensive care unit and in a domestic isolation 1,393 and finally 195 deaths (Figure 4 and Figure 5) (31). 


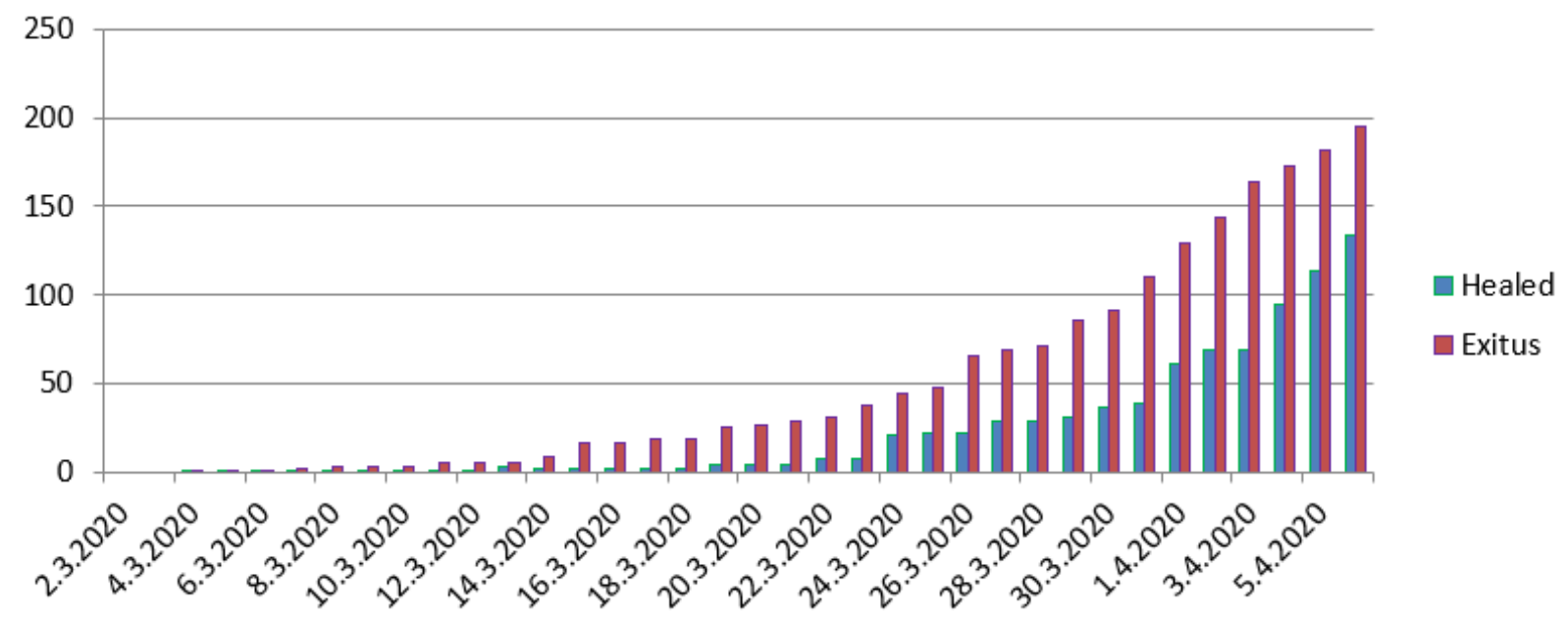

Figure 5. Graphic shows the relationship between the emergency days and the total number of the healed and the dead patients (source Bollettino epidemiologico Regione Puglia 06/04/2020, Italy)

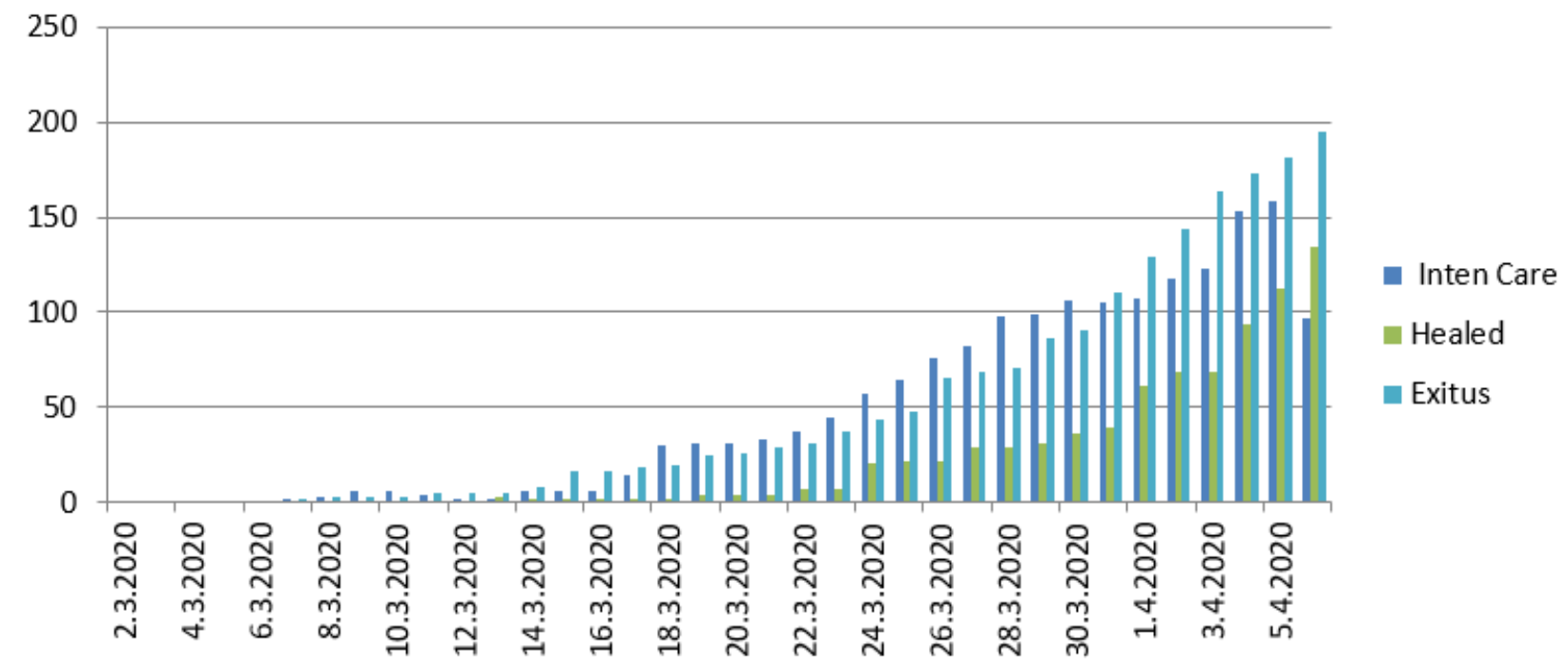

Figure 6. Graphic shows the relationship between the emergency days and the total number of the patients in Intensive care unit whit, the healed or the exitus (source Bollettino epidemiologico Regione Puglia 06/04/2020, Italy)

Emergency Departments have been early overcrowded, so non-urgent procedures have been already cancelled in order to save hospital beds, moreover in intensive care units (ICUs). The algorithm is constantly updated to meet regional directives about hot zone extension and modalities for rapid triage and COVID-19 testing on suspected patients (Figure 6).

\section{BEYOND THE HEALTH ISSUE}

The world and the Italian public health system (formerly Servizio Sanitario Nazionale) have started a battle that must be won, and we must mention though that another aspect of the Italian public health system. The report of the Evidence-Based Medicine Italian Group (formerly Gruppo Italiano per la Medicina Basata sulle Evidenze - GIMBE) Observatory entitled "Definancing 2010-2019 of the National Health Service" shows that the Italian National Health System has lost in the last ten years $€ 37$ billion of public funding, of which $€ 25$ billion in 20102015 as a result of cuttings of different financial manoeuvres and $€ 12$ billion in the period from 2015 to 2019, when less resources were allocated to health than those programmed for public finance needs. In absolute terms, public financing in 10 years has increased by 8.8 billion, growing by an average of $0.9 \%$ a year, lower than the average annual inflation rate $(1.07 \%)$. The data from the Organisation for Economic Cooperation and Development (OECD) updated to July 2019 show that Italy is below the average for both total health expenditure per capita $(3,428$ dollars vs 3,980$)$, and public expenditure (2,545 vs 3,038), ahead of only the Eastern European countries besides Spain, Portugal and Greece.

In the period 2009-2018 the public health expenditure increase was $10 \%$, compared to an average of $37 \%$. On December 2016, the Budget Law 2017 redistributed on a three years basis (2017-2019) the resources already allocated to the biennium 2017-2018: $€ 113$ billion for 2017, $€ 114$ billion for 2018 and $€ 115$ billion for 2019 .

On April 2017, the Economy and Finance Document Update Note (NADEF) expected that the health expenditure/Gross Domestic Product (GDP) ratio to decline from $6.7 \%$ in 2017 to $6.4 \%$ in 2019 , estimating a further reduction in the expenditure health/GDP ratio from $6.6 \%$ in 2017 to $6.3 \%$ in 2020 , and confirmed the gradual reduction of it extending to 2021 the $6.3 \%$ already estimated for 2020 . The 
Public Founding (Euro billions) for the Italian National Healt Care facilities

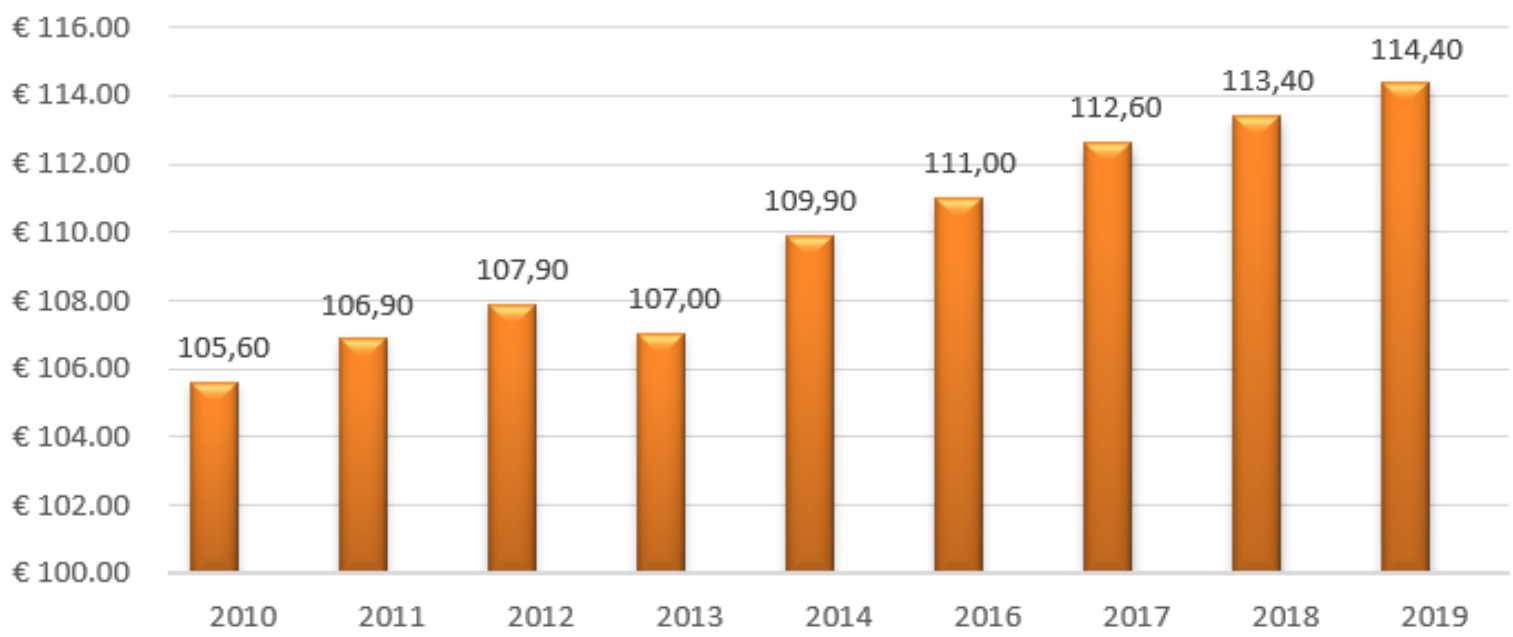

Figure 7. Graphic shows the financing of the Italian National Healthcare facilities over the last decade (source Report_Osservatorio_GIMBE)

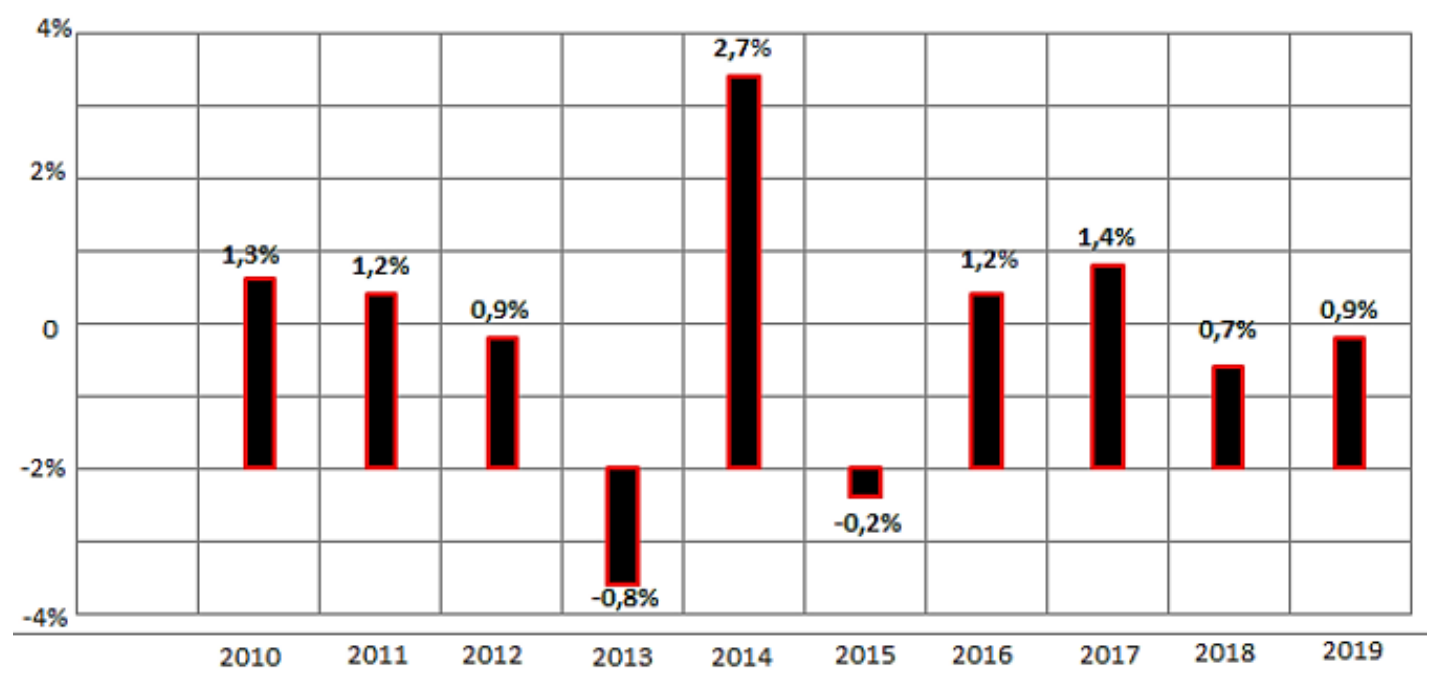

Figure 8. Graphic shows the financing of the National Healthcare facilities overall grew by an average of $0.9 \%$ per year, a rate lower than that of the average annual inflation of $1.07 \%$. Therefore, the financial increase in the last decade has not been sufficient to maintain purchasing power (source Report_Osservatorio_GIMBE)

Decree of the Ministry of Health entitled "Redetermination of the level of national health needs" of 2017 reduced the public funding of SSN by $€ 423$ million for the year 2017, and by $€ 604$ million for the year 2018 and subsequent. In DEF 2019, the health expenditure/GDP ratio remains the same as in 2018 (6.6\%) for the years 2019 and 2020, then falling to $6.5 \%$ in 2021 and $6.4 \%$ in 2022 (32).

At the time of the submission of this paper, good news has been shared regarding the development of a vaccine against SARS-CoV-2 that seems to be effective in animal models (33). The research team of the University of Pittsburgh has developed a vaccine, called PittCoVacc, (Pittsburgh CoronaVirus Vaccine), using laboratory-created viral protein fragments that can stimulate the immune response.

The researchers used an innovative approach for vaccine administration based on the use of a micro-needle system that empower it. In detail they used a plaster sizing a fingertip with 400 dissolving undercut micro-needles, each one entirely made of glucose and fragments of viral spikes proteins, that penetrate through the skin and dissolve in the epidermis.
Although not yet assessed over the long term researchers report that, like mice that received the MERS-CoV vaccine in the past, antibody levels in models vaccinated against SARS-CoV-2 appear to follow the same trend, and therefore it could produce a sufficient level of antibodies to neutralize the virus for at least a year (33). Apart from the specific health issues related to COVID-19, some authors are considering the economic and social aspects of it.

After three months from the arise of the current COVID-19 pandemics several aspects of our lifestyles are changing everywhere, with some positive effects. For example, the atmospheric pollutions are widely decreased as a lockdown consequence, wild animals are regaining their natural spaces, dietary habits are ameliorated, etc. (34,35). China and Italy, that have been the first countries with the earlier and most large number of patients, have taught to the others what to do and not do to face COVID-19 pandemics, and unexpected international collaborations arose overcoming past and actual contrasts. 
However, we agree with G. Lichfield that at the end of this period the whole world will be different (36). As for the past, worldwide will be mandatory to re-think our life, as well as the health and research funding policies to tackle with greater serenity and appropriate tools any possible future situations of health crisis that can occurr (37-29).

\section{CONCLUSIONS}

The experience of the COVID-19 crisis is currently unmasking the weakness of the national health systems worldwide, an effective rehearsal for future international sanitary crises. According WHO we must expect a potential, severe health crisis because of infectious conditions due to the increasing number of antibiotic resistant bacterial strains. All the extensive economic interventions adopted by governments and private funders in the world to support the national health systems, the biomedical research and international cooperation should become largely ordinary after the emergency to better counteract similar situations.

\section{ACKNOWLEDGEMENTS}

Be aware that this report is updated to April 6, 2020.We are thankful to all the Colleagues and all healthcare professionals on the frontline that are worldwide involved in the battle against COVID-19. However, we dedicate this paper to all the Italian doctors died as a consequence of COVID-19, whose names are reported on the website of the National Federation of Medical Councils and available at https://portale.fnomceo.it/elenco-dei-medici-caduti-nelcorso-dellepidemia-di-covid-19/

\section{REFERENCES}

1. WHO. Statement on the second meeting of the International Health Regulations (2005). Emergency Committee regarding the outbreak of novel coronavirus (2019-nCoV). Jan 30, 2020.

2. WHO. Disease outbreak news: Update. 12 January 2020.

3. WHO. Novel Coronavirus (2019-nCoV) Situation Report - 1 21 January 2020.

4. Wu Z, McGoogan JM. Characteristics of and important lessons from the coronavirus disease 2019 (COVID-19) outbreak in China. JAMA. 2020;2019:25-8. https://doi.org/ 10.1001/jama.2020.2648

5. Tyrrell DAJ, Bynoe ML. Cultivation of a novel type of common cold virus in organ culture. Br. Med. J. 1965;1:1467. https://doi.org/10.1136/bmj.1.5448.1467

6. Tyrrell DAJ, Almeida JD, Berry DM, Cunningham $\mathrm{CH}$, Hamre D, Hofstad MS, Malluci L, Mcintosh K. Coronaviruses. Nature. 1968;220:650. https://doi.org/10.1038/220650b0

7. Prete RD, Ronga L, Addati G, Magrone R, Abbasciano A, Carlo DD, Santacroce L. A Retrospective Study about the Impact of Switching from Nested PCR to Multiplex RealTime PCR on the Distribution of the Human Papillomavirus (HPV) Genotypes. Medicina (Kaunas). 2019 Jul 30;55(8). pii: E418. https://doi.org/10.3390/medicina55080418
8. Mosca A, Carucci A, Santacroce L, Schettini F, De Mattia D, Miragliotta G. Streptococcus pneumoniae nasopharyngeal colonization in young healthy children: rate of carriage, serotype distribution, and antibiotic resistance. New Microbiol. 2003 Apr;26(2):187-92.

9. Di Serio F, Lovero R, D'Agostino D, Nisi L, Miragliotta G, Contino R, Man A., Ciccone M.M., Santacroce L. Evaluation of procalcitonin, Vitamin $\mathrm{D}$ and C-reactive protein levels in septic patients with positive emocoltures. Our preliminary experience. Acta Medica Mediterr 2016;32:1911-4. https://doi.org/10.19193/0393-6384_2016_6_182

10. Charitos IA, Topi S, Castellaneta F, D'Agostino D. Current Issues and Perspectives in Patients with Possible Sepsis at Emergency Departments. Antibiotics (Basel). 2019 May 7;8(2). pii: E56. https://doi.org/10.3390/antibiotics8020056

11. D'Agostino D, Cappabianca G, Rotunno C, Castellaneta F, Quagliara T, Carrozzo A, Mastro F, Charitos IA, Beghi C. The Preoperative Inflammatory Status Affects the Clinical Outcome in Cardiac Surgery. Antibiotics (Basel). 2019 Oct 5;8(4). pii: E176. https://doi.org/10.3390/antibiotics8040176

12. Fornasin A, Breschi M, Manfredini M. Spanish Flu in Italy: New Data, New Questions. Infez Med. 2018;26(1):97-106.

13. https://www.corriere.it/cronache/20_gennaio_30/coronav irus-italia-corona-9d6dc436-4343-11ea-bdc8faf1f56f19b7.shtml

14. WHO. Novel Coronavirus(2019-nCoV) Situation Report - 11 31 January 2020.

15. WHO. Coronavirus disease 2019 (COVID-19) Situation Report -24 13 February 2020.

16. WHO. Coronavirus disease 2019 (COVID-19) Situation $\begin{array}{lllll}\text { Report } & -25 & 14 & \text { February } & 2020 .\end{array}$ https://doi.org/10.7175/cmi.v14i1.1467

17. WHO. Coronavirus disease 2019 (COVID-19) Situation Report - 3322 February 2020.

18. Coronavirus disease 2019 (COVID-19) Situation Report - 37 26 February 2020.

19. Coronavirus disease 2019 (COVID-19) Situation Report - 1122 March 2020.

20. Coronavirus disease 2019 (COVID-19) Situation Report - 77 06 April 2020.

21. Epicentro, Istituto Superiore di Sanità, L'epidemiologia per la sanità pubblicaSorveglianza Integrata COVID-19 in Italia (Ordinanza n. 640 del 27/02/2020), Aggiornamento 5 April 2020.

22. Presidenza del Consiglio dei Ministri. Available at: https://www.slideshare.net/Palazzo_Chigi/coronavirusfirmato-il-dpcm-8-marzo-2020

23. Presidenza del Consiglio dei Ministri. Available at: https://www.slideshare.net/Palazzo_Chigi/dpcm-9marzo-2020

24. Presidenza del Consiglio dei Ministri. Available at: http://www.governo.it/it/articolo/coronavirus-contefirma-il-dpcm-11-marzo-2020/14299

25. WHO. Global surveillance for human infection with coronavirus disease (COVID-2019). Available at: https://www.who.int/publications-detail/globalsurveillance-for-human-infection-with-novel-coronavirus(2019-ncov) (Accessed Jan 31, 2020).

26. WHO. Advice on the use of masks in the community, during home care, and in health care settings in the context of COVID-19. Interim guidance 19 March 2020. 
27. Epicentro, Istituto Superiore di Sanità, L'epidemiologia per la sanità pubblica, Caratteristiche dei pazienti deceduti positivi a COVID-19 in Italia, 2020.

28. WHO. Health workers exposure risk assessment and management in the context of COVID-19 virus. 4 March 2020.

29. Grasselli G, Pesenti A, Cecconi M. Critical Care Utilization for the COVID-19 Outbreak in Lombardy, Italy: Early Experience and Forecast During an Emergency Response. JAMA. 2020. https://doi.org/10.1001/jama.2020.4031

30. Rosenbaum L. Facing Covid-19 in Italy - Ethics, Logistics, and Therapeutics on the Epidemic's Front Line. N Engl J Med. 2020 Mar 18. https://doi.org/10.1056/NEJMp2005492

31. Bollettino epidemiologico Regione Puglia 06/04/2020,Italia

32. Report_Osservatorio_GIMBE_2019.07_Definanziamento_S SN

33. Kim E, Erdos G, Huang S, Kenniston TW, Balmert SC, Carey $\mathrm{CD}$, Raj VS, et al. Microneedle array delivered recombinant coronavirus vaccines: Immunogenicity and rapid translational development, EBioMedicine 2020, https://doi.org/10.1016/j.ebiom.2020.102743
34. Hauser J, Jackson A. NASA images show a de-crease in China's pollution related to coronavirus shutdown. CNN. 2020. Available at: www.cnn.com/2020/03/01/world/nasachina-pollution-coronavirus-trnd-scn/index.html

35. Gudi SK, Tiwari KK. Preparedness and lessons learned from the novel coronavirus disease. Int J Occup Environ Med 2020;11:108-12. https://doi.org/10.34172/ijoem.2020.1977

36. Leichfield G. We're not going back to normal. MIT Tech Rev. March 17, 2020.

37. Bottalico L, Charitos IA, Kolveris N, D'Agostino D, Topi S, Ballini A, Santacroce L. Philosophy and Hippocratic Ethic in Ancient Greek Society: Evolution of Hospital - Sanctuaries. Open Access Maced J Med Sci. 2019 Oct 13;7(19):3353-7. https://doi.org/10.3889/oamjms.2019.474

38. Emanuel EJ, Persad G, Upshur R, Thome B, Parker M, Glickman A, Zhang C, Boyle C, Smith M, Phillips JP. Fair Allocation of Scarce Medical Resources in the Time of Covid-19. N Engl J Med. 2020 Mar 23. https://doi.org/10.1056/NEJMsb2005114

39. Santacroce L, Bottalico L, Charitos IA. The impact of COVID19 on Italy: a lesson for the future. Int J Occup Environ Med 2020;11:e4-e5. https://doi.org/10.34172/ijoem.2020.1984 